\title{
Multiloop low bandwidth communication-based power sharing control for microgrids
}

\author{
Erum Pathan ${ }^{1}$, Afarulrazi Abu Bakar ${ }^{2}$, Mubashir Hayat Khan ${ }^{3}$, Muhammad Asad ${ }^{4}$, Haider Arshad \\ ${ }^{1}$ Department of Electronic Engineering, Quaid-E-Awam University of Engineering, Science \& Technology Nawabshah, \\ Sindh, Pakistan \\ ${ }^{2,3,5}$ Department of Electrical Power Engineering, Faculty of Electrical and Electronics Engineering, Universiti Tun \\ Husein Onn Malaysia, Batu Pahat, Johor, Malaysia \\ ${ }^{4}$ Substation Automation Engineer, NG CSD-C, Saudi Electricity Company, Riyadh, Saudia Arabia
}

\section{Article Info}

Article history:

Received Jul 5, 2020

Revised Sep 7, 2020

Accepted Sep 18, 2020

\section{Keywords:}

Adaptive virtual impedance

Distributed generation

Impedance mismatch

Low bandwidth communication

Power sharing

\begin{abstract}
In parallel-connected inverter-based microgrids, the reactive power sharing accuracy can not have satisfactory results effortlessly. Mismatch in feeder impedances of the parallel-connected inverter-based microgrids is a significant cause of inaccurate reactive power-sharing. In voltage source inverters (VSI) based microgrids, especially for the islanded mode of operation, the conventional centralized or decentralized control techniques are not much helpful to control the voltage deviations due to impedance mismatch. Mismatch of the feeder impedance is compensated by the addition of fixed virtual impedance. Whereas, the change in the virtual impedance is compensated by adaptive virtual impedance-based control techniques which are helpful to mitigate power-sharing errors, but in most of the control schemes virtual impedance-based control mechanism needs pre-knowledge of feeder impedance which increases the computational burden. This paper presents a decentralized virtual impedance-based power sharing control. In the proposed control solution to mitigate reactive power sharing errors in distributed generation (DG) units, mismatch of the parallel-connected feeder impedance is equalized by regulating the addition of equivalent impedance to each DG inverter. Proposed control technique offers an independent implementation without any pre-knowledge of the feeder impedance. Hence, the implementation of the control scheme is a straightforward and computational burden is also reduced. Simulation results show the effectiveness of the control scheme.
\end{abstract}

This is an open access article under the CC BY-SA license.

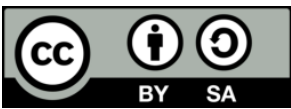

Corresponding Author:

Afarulrazi Abu Bakar

Faculty of Electrical and Electronics Engineering

Universiti Tun Husein Onn Malaysia

Batu Pahat, Johor, Malaysia. 86400

Email: afarul@uthm.edu.my

\section{INTRODUCTION}

Over the past few years distributed generation (DG), like renewable energy resources (RESs) has been widely considered in all over the world responding to rising demand for electricity and Global warming [1]. Subsequently, the implementation and operation of power electronics-based DGs connecting in parallel have many issues related to control, management and stability. DGs unit/units with connected loads and some control is referred to as microgrid system (MGs). MGs typically operates in grid-connected mode but can perform within a separate mode, i.e. the islanded mode which may be intentionally or in case of any fault 
in the grid during operation. The switching from one mode to another mode could be manual or autonomous [2]. In case of automatic islanding, the power-sharing accuracy especially the reactive power sharing accuracy, voltage and frequency adjustments are achieved by improved droop-based control schemes which are decentralized and communication free control scheme [3-5]. Droop control takes the local measurements, and it can be implemented very easily, but the mismatch in the feeder's impedance of the parallel-connected DG inverters cause reactive power sharing errors and voltage deviations. When different load conditions are applied to the same network, the reactive power and voltage deviations increase significantly even for the local loads [6,7]. Online estimator method has been implemented in [8], which estimates the voltage drop in transmission lines and voltage is then compensated to improve reactive power-sharing. However, this online estimation control scheme is applicable to the grid-connected mode of operation. If the microgrid is in islanded mode of operation, the online estimator control scheme only be implemented when it is switched to the grid-connected mode. Voltage compensation technique is used in [9] to mitigate the power-sharing inaccuracy, but the reactive power is not accurately shared, and also the stability of the system is not guaranteed. Equivalent feeder concept with the addition of virtual impedance to cover up the mismatch of the line impedance is employed in [10]. Another solution that does not depends on feeder impedance and data exchange presented in [11], which is followed by [12] and tested for various load changing conditions. The results showed that power-sharing is effectively done. In [13], virtual capacitor algorithms are introduced to show accuracy in power-sharing, but the scheme does not support the load varying conditions. Dead time concept presented in [14] for power-sharing, but the control scheme is very complicated and difficult to implement.

As shown in $[15,16]$ the virtual synchronous generator droop-based control techniques suggested for voltage source inverters (VSIs). Equal and accurate power-sharing among VSIs with parallel-connected DG inverter-based MG system in a decentralized manner has been discussed in detail. However, unfortunately, there were reactive power sharing errors caused by the mismatch of grid impedance recorded in the simulation results. At fundamental and harmonic frequencies solution for reactive power sharing errors presented in [17-19], where the VSI impedances are reshaped by adding the virtual impedance loop to avoid the mismatch impedance. The virtual impedance loop had been designed that is dependent on values of the feeder's physical impedance which can never be accurate and in case of adaptive virtual impedance the computational burden is the drawback of the control schemes. Reactive power-sharing improvement control strategy with the capacitive or inductive droop with the loop of virtual impedance implemented in [20-23], where the point of common coupling information and the line impedance measurements are much complicated and reactive power sharing errors are not removed up to the desired level. Moreover, the abrupt change in loads and plug and play feature of the microgrid system does not afford any fixed configuration. Here a proposed solution with adaptive virtual impedance-based control which calculates the real-time values of impedance and reshapes them accordingly is presented. The control mechanism is applicable to the islanded microgrids. Reactive power-sharing accuracy and voltage frequency errors are eliminated in the proposed control technique, which is easy to implement. The communication-link is used for exchanging the information between the central controller to the distributed generation units and vice versa. Microgrid central controller (MGCC) gets the information of the feeder impedance and modify the virtual impedance values accordingly to compensating the impedance mismatch. Paper is arranged as the introduction in section 1, operation of a parallel-connected inverter-based microgrid is given in Section 2. virtual impedance Based control, Proposed Adaptive Virtual Impedance multiloop control, simulation results and Conclusion are given in Section 3, 4, 5 and 6 respectively.

\section{OPERATION OF PARALLEL CONNECTED INVERTER-BASED MICROGRID}

\subsection{Micro grid structure}

In the microgrid under consideration here, there are two DG units; each unit is connected with the LC filter and local loads and load at point of common coupling (PCC). As shown in Figure 1, the central controller and main controller MGCC continuously monitor the microgrid operation and mode of operation, whether it is working under islanded or grid-connected mode. The information between MGCC and the DG units are carried out through the communication link that utilizes a very low bandwidth communication. A static transfer switch (STS) is inserted between the DG inverters and the main grid and PCC. Power-sharing errors are rectified automatically by the main grid in case of grid-connected mode. In an islanded mode of operation with parallel-connected inverters, the reactive power-sharing is a big concern in parallel connected inverter-based microgrids. So, the voltage and frequency deviations are the main issues when the microgrid is transferred to the islanded mode of operation as well as the abrupt change in the load conditions. 


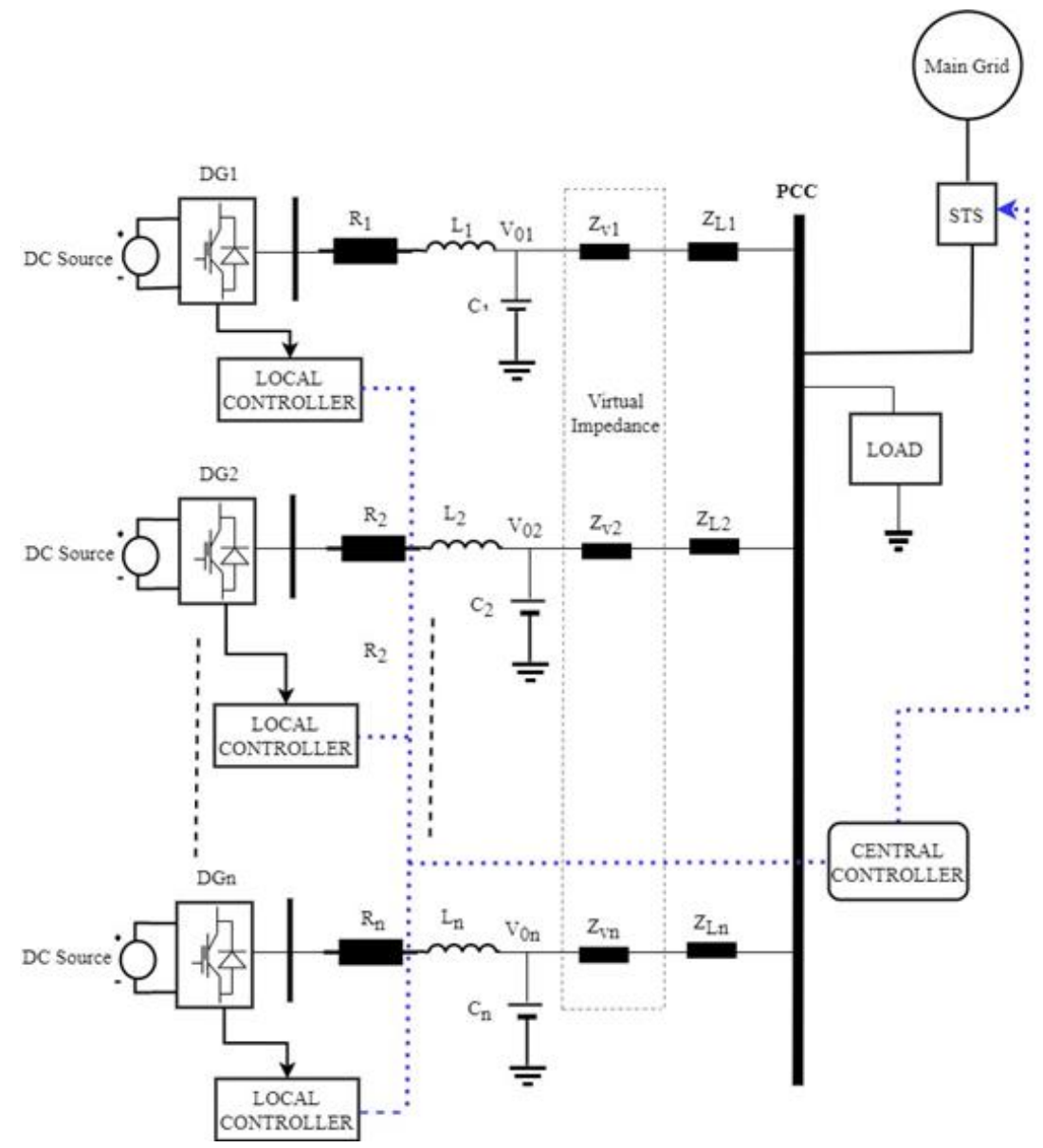

Figure 1. Microgrid with the local and central controller

\subsection{Conventional droop control}

Power frequency $(\mathrm{P}-\omega)$ droop curves are shown in Figure 2. In VSI model, the magnitude of frequency and voltage is regulated through P- $\omega$ droop control in islanded microgrids [24, 25]. Given the below (1) and (2) shows the relation between power and frequency.

$$
\begin{aligned}
& \omega=\omega_{o}-m P \\
& m=\frac{\Delta \omega}{P_{\max }}
\end{aligned}
$$

Where $\omega_{0}$ and $\omega$ are the nominal and angular frequency, respectively. $\mathrm{m}$ and $\mathrm{P}_{\max }$ are the droop coefficient and maximum active power. Similarly, for the reactive power, the relation between voltage and reactive power is given as:

$$
\begin{aligned}
& V=V_{o}-n Q \\
& n=\frac{\Delta V}{Q_{\max }}
\end{aligned}
$$

Where $\mathrm{V}_{\mathrm{o}}$ and $\mathrm{V}$ are the nominal and angular voltages, respectively. $\mathrm{n}$ and $\mathrm{Q}_{\max }$ are the droop coefficient and maximum reactive power.

From Figure 2, it is clear that whenever there is a smaller droop slope the larger power is provided by the DG unit. Whereas the voltage and frequency of the DG units connected in parallel are the same. During steady-state conditions, the system can easily attain the active power-sharing because of the consistent frequency of the DG units connected in parallel in a Microgrid. However, the reactive power-sharing is not easily attained because of the mismatch in DG feeders. 


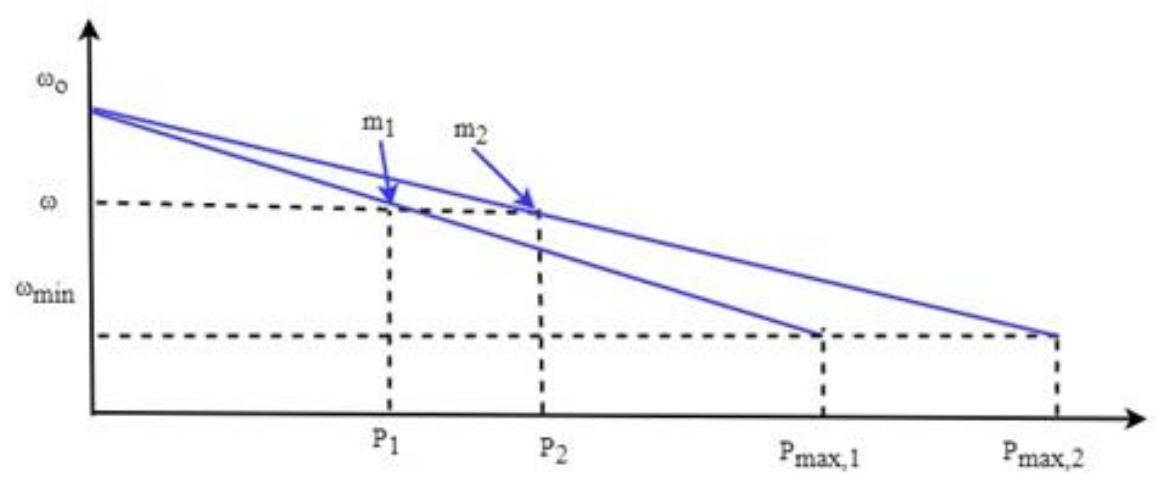

Figure 2. P- $\omega$ droop control

\subsection{Reactive power sharing analysis}

The voltage drop across the feeders and power-sharing deviations are addressed in [26, 27]. The mathematical expression for Voltage drop is given as:

$$
V=\frac{R P+X Q}{V_{o}}
$$

Where the RP and XQ are the resistance and reactance of the $\mathrm{P}$ and $\mathrm{Q}$ respectively and $\mathrm{V}_{\mathrm{o}}$, the output voltage of the DG unit. Considering two DG inverters DG1 and DG2 the above equation can be written as:

$$
\begin{aligned}
& \Delta V_{1}=\frac{R_{1} P_{1}+X_{1} Q_{1}}{V_{o}} \\
& \Delta V_{2}=\frac{R_{2} P_{2}+X_{2} Q_{2}}{V_{o}}
\end{aligned}
$$

Mismatch in the feeder impedance is represented as follows:

$$
\begin{aligned}
& \Delta X_{1}=X_{1}-X_{2} \\
& \Delta R_{1}=R_{1}-R_{2}
\end{aligned}
$$

From (5), the active and reactive powers of the DG1 and DG2 at steady state can be expressed as:

$$
\begin{aligned}
& \Delta V_{1}=\frac{(X+\Delta X) Q_{1}+(R+\Delta R) P_{1}}{V_{o}}=\frac{X Q_{1}+R P_{1}}{V_{o}}+\frac{\Delta X Q_{1}+\Delta R P_{1}}{V_{o}}=\Delta V_{1}+\varphi V_{1} \\
& \Delta V_{2}=\frac{\left.(X+\Delta X) Q_{2}+(R+\Delta R) P_{2}\right)}{V_{o}}=\frac{X Q_{2}+R P_{2}}{V_{o}}+\frac{\Delta X Q_{2}+\Delta R P_{2}}{V_{o}}=\Delta V_{2}+\varphi V_{2}
\end{aligned}
$$

Where $\Delta V_{1}$ and $\Delta V_{2}$ are the voltage drop across the feeder 1 and feeder 2 connected with the DG1 and DG2 respectively. $(X+\Delta X)+(R+\Delta R)$ are the voltage drops across each feeder, and the term $\varphi V$ is the voltage drop mismatch.

\section{VIRTUAL IMPEDANCE BASED CONTROL}

Addition of impedance to mitigate the mismatch in feeder impedance is compensated by the addition of a suitable value of virtual impedance is shown in Figure 3. The concept of virtual impedance-based control mechanism where the virtual impedance is employed to mitigate the impedance mismatch of the feeder connected to the parallel-connected inverter-based microgrid system. The virtual impedance improves the reactive power sharing deviations, which at that instant occur due to the impedance mismatch of feeders connected to the network. As illustrated in the given Figure 3, the instantaneous voltage $V_{\text {Droop }}$ can be obtained from the (1) and (3), using voltage and frequency terms, 


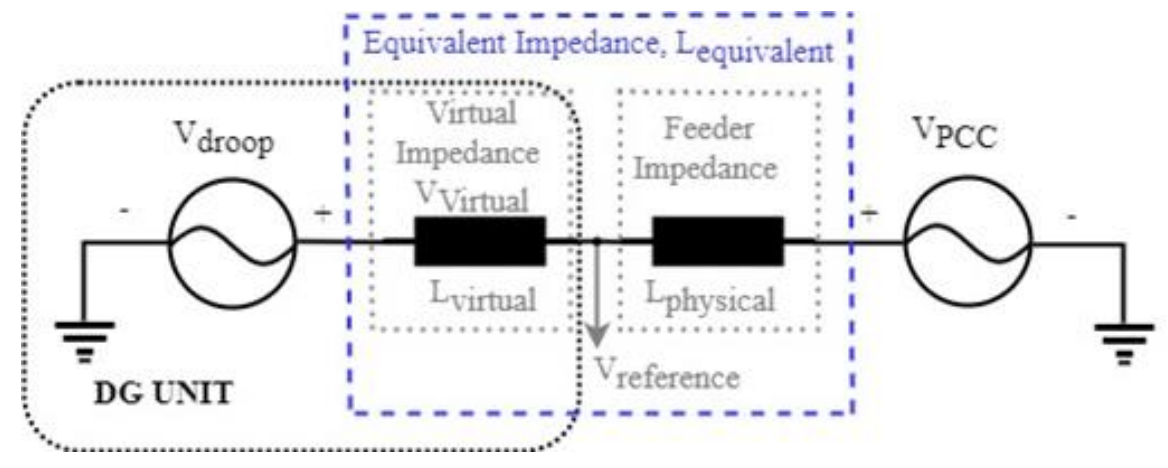

Figure 3. The equivalent impedance of DG unit

$V_{\text {Droop }}=V \sin \left(\int \omega d t\right)$

The total impedance of the feeder is the combination of Physical and virtual impedance so,

$L_{\text {Total }}=L_{\text {Physical }}+L_{\text {Virtual }}$

Corresponding voltage drop considering the line current is given as:

$V_{\text {Virtual }}=-\omega L_{\text {Virtaul }} I_{\text {line }}$

The voltage and current relation are expressed as;

$V_{L(t)}=\frac{L\left(d i_{L(t)}\right)}{d t}$, when $i_{L(t)}=I_{\text {maximum }} \sin (\omega t)$

$V_{L}=\omega L I_{\text {maximum }} \sin \left(\omega t+90^{\circ}\right)$

Finally, the voltage reference with $V_{\text {irtual }}$ and $V_{\text {Droop }}$ can be expressed as:

$$
V_{\text {Ref }}=V_{\text {Droop }}-V_{\text {Virtual }}
$$

Where the reference voltage is calculated as the difference of droop voltage and virtual impedance voltage.

\section{PROPOSED ADAPTIVE VIRTUAL IMPEDANCE CONTROL}

Virtual impedance is dependent on pre-knowledge of feeder impedance at every time interval with fix values. Calculation of the accurate knowledge of the feeder impedance in real-time may always be not accurately calculated, and the error chances are high. Moreover, the MGs do not afford any static configuration because the connected load are not always same, it keeps on changing, and the MGs should have online impedance estimation, but unfortunately, the online estimation technique makes the controller very complex. So, to avoid the complexity of controller and computational burden, an algorithm that should not depend on pre-knowledge of feeder impedance connected to the system is proposed here. Figure 4 shows the adaptive virtual impedance control technique. The MGCC gets all the information through a low bandwidth communication link related to reactive power outputs, i.e. $Q_{1}, Q_{2}$ up to $Q_{n}$ in this control technique. The total $\mathrm{Q}$ is obtained at MGCC, and the value of $\mathrm{Q}$ for each inverter can be determined as;

$$
Q^{*}=\frac{Q_{\text {Total }}}{\sum_{j=1}^{n} Q_{\text {Rated } j}} Q_{\text {Rated }}
$$

Where $Q^{*}$ is the reactive power demand and (18) shows the reactive power demand calculation for inverters connected in parallel in MGs individually. The difference of the reactive power demand $\left(Q^{*}\right)$ and reactive power $(Q)$, which is utilized to compensate for the DG virtual impedance. The compensation is done through an Integral controller. $L_{\text {Virtual }}$ for DG inverter can be obtained as; 


$$
L_{\text {Virtual }}=L_{\text {Virtual }}^{*}+\frac{K_{i Q}}{S}\left(Q-Q^{*}\right)
$$

Where $\mathrm{L}_{\text {Virtual }}$, is the fixed virtual impedance and $\mathrm{K}_{\mathrm{iQ}}$ is the integral gain (IG). The IG is set to set virtual reactance.

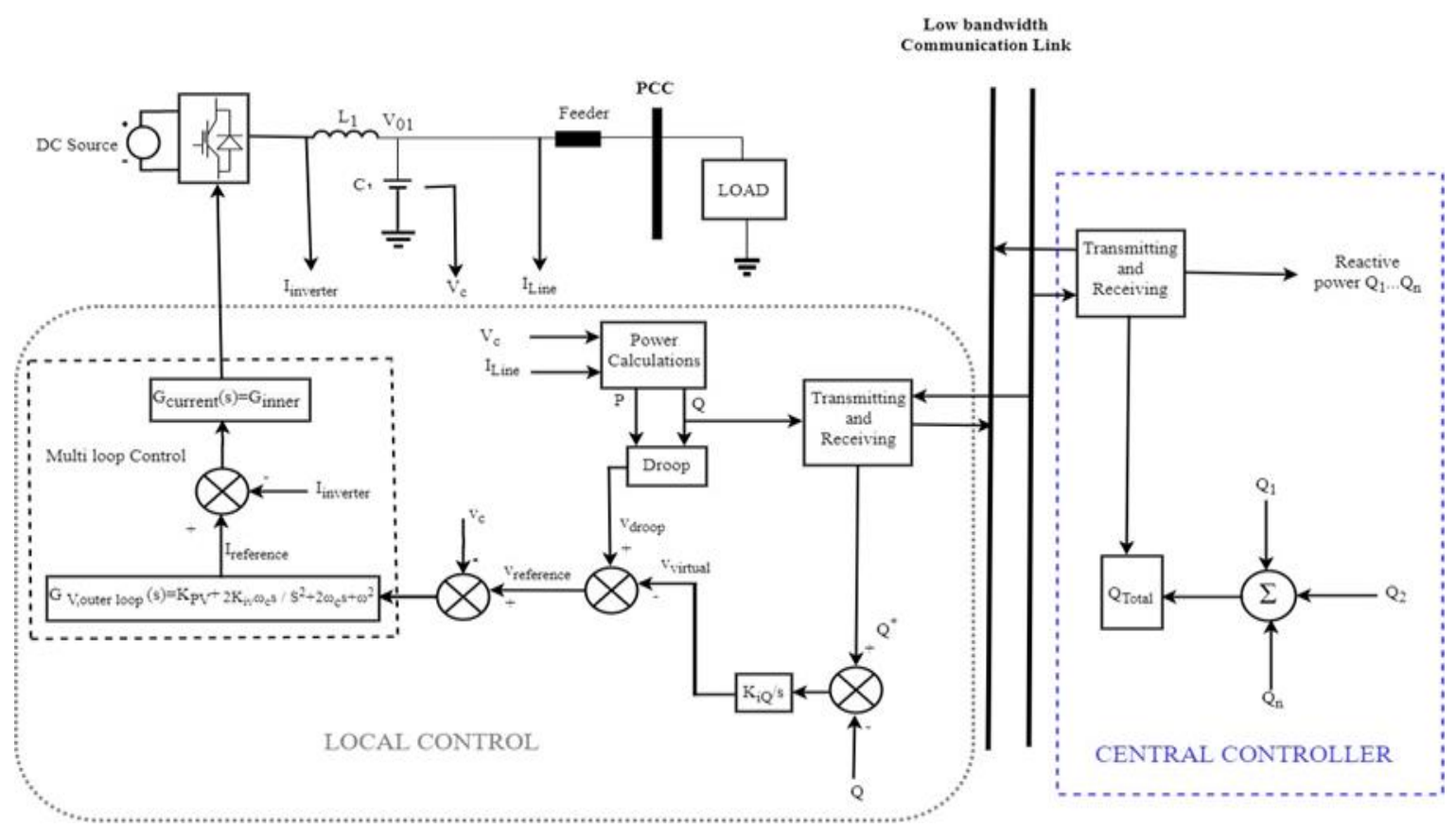

Figure 4. The proposed multiloop control scheme

In this paper, a voltage tracking technique to mitigate the reactive power sharing errors is proposed, which is implemented through the multiloop voltage controller. The reference for voltage is changed, as given in (20), the proportional resonant (PR) controller is adjusted accordingly.

$$
G_{V, \text { outer loop }}=K_{P V}+\frac{2 K_{i v} \omega_{c} s}{S^{2}+2 \omega_{c} s+\omega_{D G}^{2}}
$$

Where $\mathrm{K}_{\mathrm{PV}}$ is outer loop proportional gain, $\mathrm{K}_{\mathrm{iv}}$, PR controller gain and $\omega_{\mathrm{c}}$ is the cut-off frequency of PR controller. As the inner loop control gain is to be taken as $G_{\text {current }}(s)=K_{\text {inner }}$ for the current of the filter inductor.

\section{SIMULATION RESULTS}

The proposed multiloop virtual impedance control scheme is tested and verified through simulation results. The system parameters are listed in Table 1 given below. Two DG inverters DG1 and DG2 are tested under various conditions. The MGCC exchanges the required information through low bandwidth communication. Under the same power rating and different feeder impedances, the MG model is tested to prove its efficiency. From Figure 5 (a) and Figure (b) it is shown clearly from the figure that active and reactive powers are delivered by each DG inverter connected to the MGs in parallel. In an ideal case, both the DG inverters should have to share equal power but due to mismatch in feeder impedance power-sharing is not accurate as per DG inverters capacity. It can be seen that there are steady-state deviations inactive powersharing. In impedance mismatch conditions, $p$-f droop does not show power-sharing accuracy due to the feeder's different resistances. In Figure 5 (a) steady-state deviations in $\mathrm{P}$ sharing. Unlike $\mathrm{P}$, the $\mathrm{Q}$ sharing accuracy is dependent to the system frequency which is globally taken as a fixed quantity that is the reason $\mathrm{Q}$ sharing accuracy is better than $\mathrm{P}$ as given the Figure 5 (b). Initially, reactive power-sharing shows accuracy with comparison to the active power-sharing because $\mathrm{Q}$ depends on the frequency. When load changes applied at $\mathrm{t}=1.53$ second, that changed the waveform of reactive power as well as the active power sharing accuracy deviates more. Results in Figure 6 (a) and (b) shows the performance of the proposed control 
scheme to mitigate the power-sharing deviations. It is clear from the figure that P\&Q deviations were removed to large extant after applying the virtual impedance multiloop technique.

Table 1. System parameters

\begin{tabular}{|c|c|}
\hline Description & Value \\
\hline DC-Link voltage, $\mathrm{V}$ & 150 Volts \\
\hline Switching frequency, $\mathrm{f}_{\mathrm{s}}$ & $10 \mathrm{kHz}$ \\
\hline Output Filter Parameters, R, L and C & $0.1 \Omega, 2 \mathrm{mH}, 40 \mu \mathrm{F}$ \\
\hline Nominal Voltage Amplitude, $\mathrm{V}_{\mathrm{o}}$ & 311 Volts \\
\hline LPF Cut-off frequency, $\omega_{\mathrm{c} \text { and }}$ Nominal Frequency, $\mathrm{f}$ & $10 \mathrm{~Hz}$ and $50 \mathrm{~Hz}$ \\
\hline Frequency, Voltage droop coefficients, m,n (Rad/Sec.w, V/var) & $0.002,0.0025$ \\
\hline Integral Gain, $\mathrm{K}_{\mathrm{iQ}}$ and Fix virtual impedance $\mathrm{L}^{*}$ Virtual & $1 \mathrm{mH}$ and 0.00006 \\
\hline Outer loop Proportional gain, $K_{\mathrm{pv} \text { and }}$ Inner loop Proportional gain, $\mathrm{K}_{\mathrm{inner}}$ & 0.1 and 25 \\
\hline Resonant controller gain, $\mathrm{K}_{\mathrm{iv}}$ & 18 \\
\hline DG Feeder 1 parameters and DG Feeder 2 parameters & $3.0 \mathrm{mH}, 0.2 \Omega^{\prime} \& 2.0 \mathrm{mH}, 0.1{ }^{\prime} \Omega$ \\
\hline
\end{tabular}

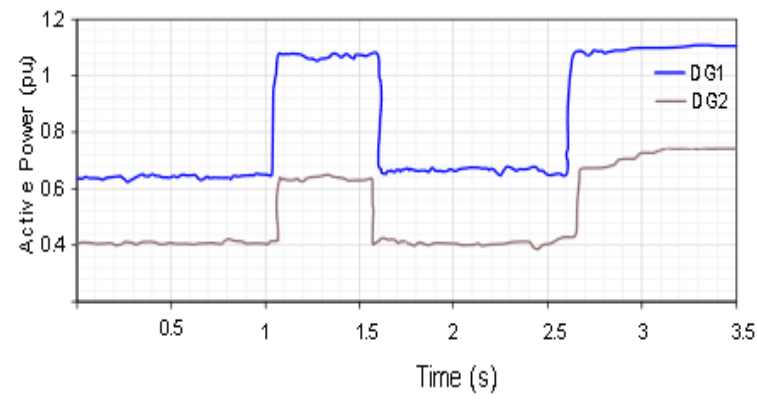

(a)

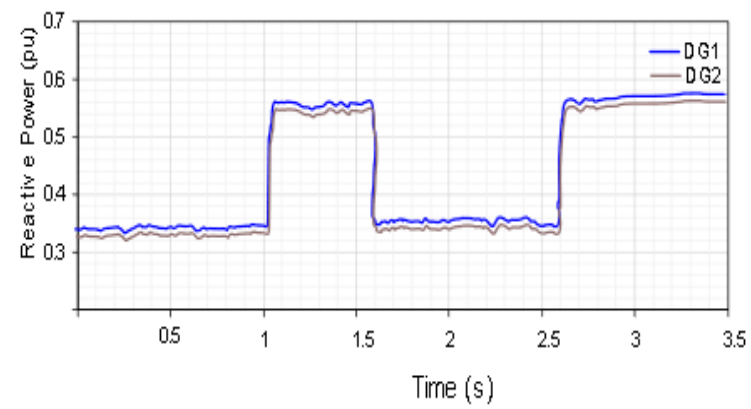

(b)

Figure 5. Conventional droop control

At $\mathrm{t}=0.54$ seconds, the proposed virtual impedance multi loops control is applied to MGs. P \& $\mathrm{Q}$ sharing accuracy is achieved after a short transient and even after load step changes the accuracy in powersharing does not validate as shown in the figure the controller is enabled at $\mathrm{t}=0.5$ second and disabled at $\mathrm{t}=2$ seconds.

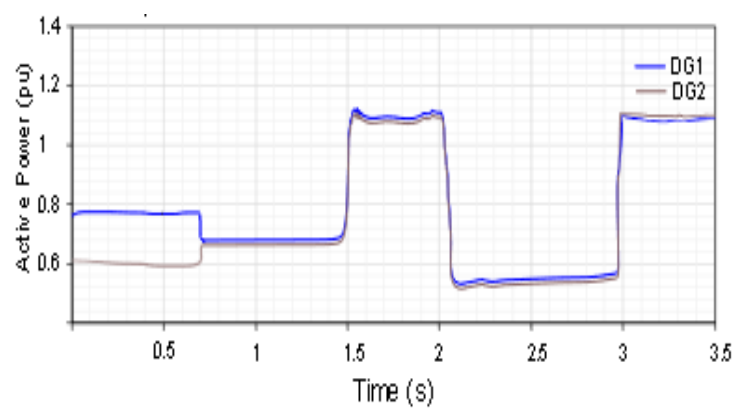

(a)

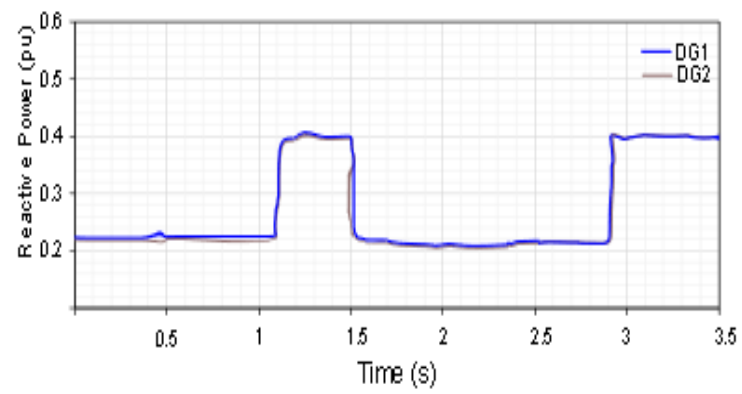

(b)

Figure 6. Multiloop control with different load variations

In Figure 7 (a), Figure 7 (b) and Figure 7 (c) it can be seen that virtual impedance loop is capable of keeping the last value even after disabling the proposed controller and the voltage at PCC is in acceptable shape and range. So, the effect of feeder impedance mismatch is removed by implementing the proposed control scheme. 


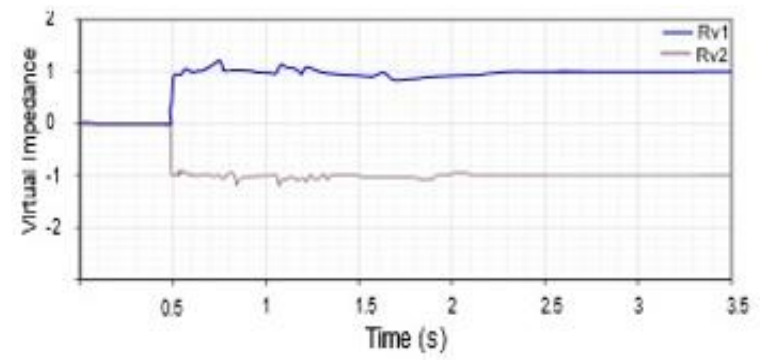

(a)

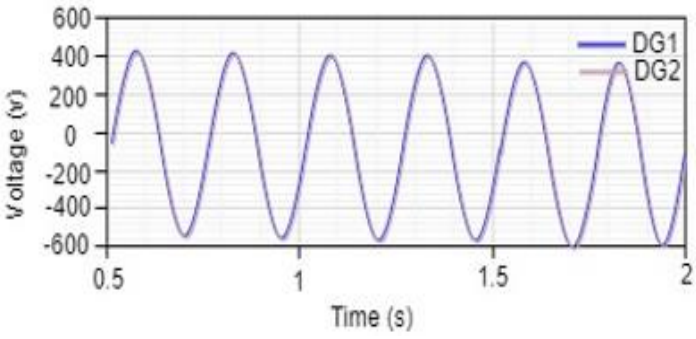

(b)

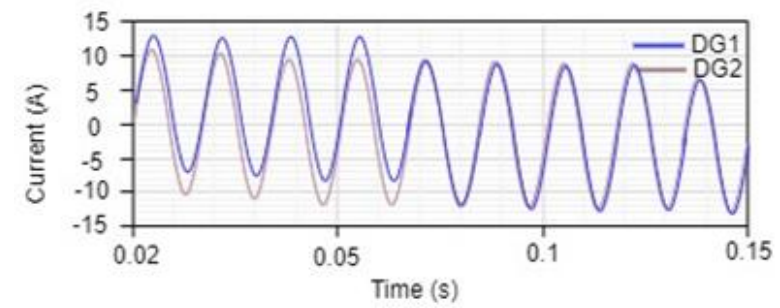

(c)

Figure 7. Virtual impedance and voltage at PCC

\section{CONCLUSION}

The power sharing accuracy in an islanded microgrid is a big challenge, especially the reactive power sharing accuracy. This paper proposed a low bandwidth communication based multiloop virtual impedance-based control strategy, which is implemented to two DG inverters with the same capacity and different impedances. The proposed control scheme is capable of changing adaptively when there is load change. Once the controller mitigates the mismatch of feeder impedance, the impedance values of the controller remain the same even after the controller is disabled. The proposed technique does not need any pre-knowledge of the feeder impedance, avoid complexity and computational burden. Moreover, the system stability is not affected even a low communication bandwidth is used in the system to establish a communication link between DG inverters and Microgrid central controller.

\section{ACKNOWLEDGEMENTS}

The authors would like to thank the Ministry of Higher Education, Malaysia, for supporting this research under the Research Fund E15501, Research Management Centre, UTHM.

\section{REFERENCES}

[1] M. Bajaj and A. K. Singh, "Grid integrated renewable DG systems: A review of power quality challenges and state-of-the-art mitigation techniques," Int. J. Energy Res., vol. 44, no. 1, pp. 26-69, 2020.

[2] J. Liu, Y. Miura, H. Bevrani, and T. Ise, "A Unified Modeling Method of Virtual Synchronous Generator for Multi-Operation-Mode Analyses,” IEEE J. Emerg. Sel. Top. Power Electron., 2020.

[3] M. H. Khan, S. A. Zulkifli, E. Pathan, E. Garba, R. Jackson, and H. Arshad, "Decentralize power sharing control strategy in islanded microgrids," International Journal of Electrical Engineering and Computer Science, vol. 20, no. 2, pp. 752-760, 2020.

[4] R. Razi, M. C. Pham, A. Hably, S. Bacha, Q. T. Tran, and H. Iman-Eini, "Robust hybrid control of parallel inverters for accurate power-sharing in microgrid," Proc. IEEE Int. Conf. Ind. Technol., pp. 860-865, 2020.

[5] Z. Afshar, M. Mollayousefi, S. M. T. Bathaee, M. T. Bina, and G. B. Gharehpetian, "A Novel Accurate Power Sharing Method Versus Droop Control Include Autonomous Microgrids with Critical Loads," IEEE Access, vol. 7, pp. 89466-89474, 2019.

[6] C. Dou, Z. Zhang, D. Yue, and M. Song, "Improved droop control based on virtual impedance and virtual power source in low-voltage microgrid," IET Gener. Transm. Distrib., vol. 11, no. 4, pp. 1046-1054, 2017.

[7] Y. Liu et al., "A reactive power-voltage control strategy of an AC microgrid based on adaptive virtual impedance," Energies, vol. 12, no. 16, 2019.

[8] A. Sardashti, A. Ramezani, H. S. Nezhad and A. Moradmand, "Observer-based Sensor Fault Detection in Islanded AC Microgrids Using Online Recursive Estimation," 2019 6th International Conference on Control, Instrumentation and Automation (ICCIA), Sanandaj, Iran, 2019, pp. 1-6. doi: 10.1109/ICCIA49288.2019.9030821. 
[9] J. Zhou and P. T. Cheng, "A modified Q-V droop control for accurate reactive power sharing in distributed generation microgrid," IEEE Trans. Ind. Appl., vol. 55, no. 4, pp. 4100-4109, 2019.

[10] A. A. Nazeri, P. Zacharias, F. M. Ibanez, and S. Somkun, "Design of proportional-resonant controller with zero steady-state error for a single-phase grid-connected voltage source inverter with an LCL output filter," 2019 IEEE Milan PowerTech, pp. 1-6, 2019.

[11] D. K. Dheer, Y. Gupta, and S. Doolla, "A Self Adjusting Droop Control Strategy to Improve Reactive Power Sharing in Islanded Microgrid," IEEE Trans. Sustain. Energy, vol. 3029, no. c, pp. 1-1, 2019.

[12] Y. Gupta, K. Chatterjee, and S. Doolla, "A Simple Control Scheme for Improving Reactive Power Sharing in Islanded Microgrid,” IEEE Trans. Power Syst., vol. 35, no. 4, pp. 3158-3169, 2020.

[13] H. Xu, C. Yu, C. Liu, Q. Wang, F. Liu, and F. Li, "An Improved Virtual Capacitor Algorithm for Reactive Power Sharing in Multi-Paralleled Distributed Generators," IEEE Trans. Power Electron., vol. 34, no. 11, pp. 10786 $10795,2019$.

[14] Y. Qi, J. Fang and Y. Tang, "Utilizing the Dead-Time Effect to Achieve Decentralized Reactive Power Sharing in Islanded AC Microgrids," in IEEE Journal of Emerging and Selected Topics in Power Electronics, vol. 8, no. 3, pp. 2350-2361, Sept. 2020. doi: 10.1109/JESTPE.2019.2904077.

[15] D. Simonetti, E. Simonetti, Z. Szantoi, A. Lupi, and H. D. Eva, "First Results from the Phenology-Based Synthesis Classifier Using Landsat 8 Imagery,” IEEE Geosci. Remote Sens. Lett., vol. 12, no. 7, pp. 1496-1500, 2015.

[16] M. Eskandari, L. Li, M. H. Moradi, P. Siano, and F. Blaabjerg, "Active Power Sharing and Frequency Restoration in an Autonomous Networked Microgrid," IEEE Trans. Power Syst., vol. 34, no. 6, pp. 4706-4717, 2019.

[17] W. Deng, N. Dai, K.-W. Lao, and J. M. Guerrero, "A Virtual-Impedance Droop Control for Accurate Active Power Control and Reactive Power Sharing Using Capacitive-Coupling Inverters,” IEEE Trans. Ind. Appl., vol. 9994, no. c, pp. 1-1, 2020.

[18] Y. Qi, P. Lin, Y. Wang, and Y. Tang, "Two-dimensional impedance-shaping control with enhanced harmonic power sharing for inverter-based microgrids," IEEE Trans. Power Electron., vol. 34, no. 11, pp. 11407-11418, 2019.

[19] T. V. Hoang and H. H. Lee, "A Distributed Harmonic Power Sharing Strategy for Islanded Microgrids," ICPE 2019-ECCE Asia-10th Int. Conf. Power Electron.-ECCE Asia, pp. 230-235, 2019.

[20] K. Sabzevari and S. Karimi, et al., "Modified droop control for improving adaptive virtual impedance strategy for parallel distributed generation units in islanded microgrids," International Transactions on Electrical Energy System, vol. 29, no. 1, pp. 1-16, 2018.

[21] R. An, Z. Liu, and J. Liu, "Modified adaptive virtual impedance method to compensate mismatched line impedances in microgrids," Conf. Proc.-IEEE Appl. Power Electron. Conf. Expo.-APEC, vol. 2019-March, pp. 1109-1114, 2019.

[22] B. Liu, Z. Liu, J. Liu, R. An, H. Zheng, and Y. Shi, "An Adaptive Virtual Impedance Control Scheme Based on Small-AC-Signal Injection for Unbalanced and Harmonic Power Sharing in Islanded Microgrids," IEEE Trans. Power Electron., vol. 34, no. 12, pp. 12333-12355, 2019.

[23] W. Hao, C. Zheng, Q. Wang, and T. Rui, "Droop control method of inverter based on variable virtual impedance," Proc. 14th IEEE Conf. Ind. Electron. Appl. ICIEA 2019, pp. 1167-1172, 2019.

[24] A. E. M. Bouzid, P. Sicard, H. Chaoui, A. Cheriti, M. Sechilariu, and J. M. Guerrero, "A novel Decoupled Trigonometric Saturated droop controller for power sharing in islanded low-voltage microgrids," Electr. Power Syst. Res., vol. 168, pp. 146-161, 2019.

[25] A. Villalon, C. Munoz, R. Aliaga, J. Munoz, M. Rivera, and P. Zanchetta, "Power sharing control of islanded ac microgrid considering droop control and virtual impedance," Proc. IEEE Int. Conf. Ind. Technol., pp. 1139-1144, 2020.

[26] L. Lin, H. Ma, and Z. Bai, "An Improved Proportional Load-Sharing Strategy for Meshed Parallel Inverters System with Complex Impedances," IEEE Trans. Power Electron., vol. 32, no. 9, pp. 7338-7351, 2017.

[27] Y. Hu, J. Xiang, Y. Peng, P. Yang, and W. Wei, "Decentralised control for reactive power sharing using adaptive virtual impedance," IET Gener. Transm. Distrib., vol. 12, no. 5, pp. 1198-1205, 2018. 